\title{
El sino de la modernidad: la búsqueda interminable de certezas
}

\author{
- Luis Armando Gonzólez*
}

\begin{abstract}
A Ariadna
"Podras degenerar a lo inferior, con los hrusos; podrais realizarte a la par de las cossas divinas, por an misma decision"

(iouvanni Pi(o) i)!: i.a Mirani)(u.a

"El ideal del renacimicente es la restantacion de las normas paganas en las hellas letras, en la filosofia, a'n a se'ntimicente y e'n la moral; es al abandono de las promessas hautismales y. su total resersion"
\end{abstract}

(itorgit: SANIAYANA

"No me dirijo simo a persomas capace's de entenderme', y éstas hahrin de lecerme sin peligro"

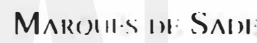

"El rechazar la muerte, el desero de duracioin y de transparencia, son los resortes de todas cestas locuras, sublime's o pucrile's"

Al.Bt:ki C'AMUs 


\section{Introducción}

Por diversas vías y desde distintos autores ha cobrado aceptación la tesis de que con la modesnidad -esa época quc con sus peculiares características económicas, políticas y culturales se inicia en el Renacimiento - se generó lo que E. Bloch Ilamó un "giro epocal"”. ¿Qué fuc lo propio de esc giro epocal"? En lo fundamental, la orfandad del individuo ante un universo abierto $\mathrm{e}$ infinito que se abría ante sus ojos y al que tenía que arrancarle sus secretos. El "mundo cerrado" que caracterizó a la Edad Media, con sus certezas, comenzaba a ser socivado por preguntas y actitudes que precisamente iban a conlracorriente de esas certezas. Al paso que las certezas vigentes eran cuestionadas, se iniciaba un proceso de búsqueda de otras que reemplazaran a las que se derrumbaban. Comenzaba a construirse uno de los pilares de la modernidad: la búsqueda de un referente que sirviera de punto de apoyo seguro a ese individuo que se las tenía que ver, sin más fuerzas que las suyas, con un "universo abierto".

Lo que comenzó a operarse en los albores de la modernidad - y que sacudió en sus cimientos a la conciencia curopea - fuc el paso del "mundo cerrado al universo infinito" (A. Koyré) ${ }^{4}$. Estc proceso —que alcanza en los siglos XVII y XVIII una de sus mejores expresiones tanto en la ciencia como en la filosofiaadquiere su impulso inicial en la mentalidad — la cultura - que se gesta en cl Renacimiento". "Si se quisiera resumir en una frase la mentalidad del renacimiento - dice Koyré-, yo propondría la fórmula: todo es posihle. El único problema es saber si "todo es posible" en virtud de intervenciones de luerzas sobrenaturales... o si se rechaza la intervención de fuerzas sobrenalurales para decir que todo es natural o que incluso los hechos milagrosos se explican por una acción de la naturaleza; es en esta naturalización mágica de lo maravilloso en lo que consiste la que se ha llamado "el naturalismo" del Renacimiento"”.

Una de las caras de este "todo es posible" es, como señala Koyré, "la curiosidad sin límites, la agudeza de visión y el espíritu de aventura"7. La otra carra es la ausencia de seguridades últimas acerca de la realización de ese que se cree posible. Y justamente es esa ausencia de seguridades lo que se va a convertir en el acicate para su búsqueda. De lo que se trata en la modernidad que se inicia es de huscar certezas, ante todo para la acción sobre el mundo. Estc es camino que comienza a recorrerse en Europa a partir del giro epocal que opera con el Renacimiento. La ciencia del siglo XVII marca un hito decisivo en la configuración de la nueva época ${ }^{x}$ Los cambios operados durante ese siglo se pueden reducir -según Koyré- a dos acciones fundamentales: la destrucción del cosmos y la geometrización del espacio. Es decir, "la sustitución de la concepción del mundo como un todo finito y bien ordenado... por el de un universo o aun infinito que ya no estaba unido por subordinación natural, sino que sc unificaba tan sólo mediante la unificación de sus leyes y componentes últimos y básicos. La segunda sustitución es la de la concepción aristotélica del espacio (...) por el de la 
geometría euclidea (...) que, a partir de entonces, pasa a considerarse idénlica al espacio real del mundo"'".

En esta dinámica cultural, el pensamiento hegeliano -y más en general, el pensamiento idealista alemán- conslituye uno de los momentos cimeros del proceso de reflexión filosófica que se inició en los albores mismos de la modernidad. Pues bien, esta afirmación obliga a delenerse en la palabra modernidad, cuya ambigüedad es de sobra conocida. ¿A qué se refiere la palahra "modernidad""? Ante todo - y dicho brevemente-, designa una época histórica - la dominada por el capitalismo- que se inicia aproximadamente hacia el siglo XVI, cuando los grandes comerciantes europeos comienzan a inverlir en actividades manufactureras'", y que llega hasla la época actual, cuando el capitalismo se erige todopoderoso sobre el conjunto del plancta. Es por ello que (ieorge Santayana pudo decir que "el hombre moderno o romántico es un aventurero: le interesa menos lo que pueda encontrar que el señuelo de la húsqueda, y sus esperanzas, conjeturas y experiencias al realizar la búsqueda" "I

La palabra designa lambién, en segundo lugar, una tradición cultural caracterizada por la crílica apasionada de sí misma'", que se inicia en el siglo XV con el Renacimiento y que para muchos está locando fondo en el momento actual. con la llamada crisis de la modernidad. Es esla segunda acepcion de la palahra "modernidad" la que nos interesa resaltar en estas piginas, pues es en la modernidad como "Iradición cullural" que se inscribe y adquieren sentido como lenómeno cultural las creaciones filosóficas que, con Marcilio Fïccino y (iiovanni Pico de la Mirándola", se abrieron paso con el "giro epocal" que mareó el inicio de la época moderna. Por tanlo, la pregunta que cahe hacerse es la siguiente: ¿cuáles son los prohlemas filosólicos que se ventilan en los inicios de la modernidad? Esla pregunla supone recuperar a Ficcino y a Pico de la Mirindola, dos figuras claves del Renacimiento y dos liguras que anuncian lúcidamente los problemas culturales de la nueva época en la cual lentamente se lue abriendo paso la idea de que "una lloreciente economía de mercado constituiría la base de un orden polílico en el que quedarian asegurados los derechos y liberlades humanas"..1.

\section{Los inicios de la "búsqueda" moderna}

Como señala Koyré, el cambio que se operó desde el mundo cerrado hacia el universo infinito no surgió de la nada. Hubo una etapa de "preparación" del cambio cultural con el que se inauguró la modernidad. Uno de los ejes de esta etapa preparatoria lo constituyó la recuperación del neoplatonismo y su relectura en una nucva situación histórica.

Pues bien, conviene recordar que en el marco de la crisis una importante crisis en el imperio romano - hacia los siglos II y III d C - se produce una

El sino de la modernidad: la búsqueda interminable de certezos 
vuelta a las tradiciones helénicas (griegas). Sobre lodo, se recupera a Platón, pero con un fuerte énfasis en la teoria del conocimiento. Justamente, al movimiento que lleva á la aclualización de la tradición platónica recibe el nombre de "neoplatonismo", el cual puede ser visto como un puente entre el racionalismo griego y el racionalismo moderno.

Los neoplatónicos tienen un representante por excelencia: Plotino (2014-27) d. C.), autor que en la teoría platónica de las ideas como lo más importante de la realidad. Hizo énfasis en la "espiritualización" de la realidad y proclamó la "renuncia del cuerpo". La "realidad espiritual" tiene una jerarquía, en cuya cima está lo bueno o el bien: Io "Uno-todo". Ese "Uno-todo" se desborda hacia el mundo y lo ilumina, lo cual hace posible su cognoscibilidad. Las "almas individuales" tienen que elevarse, en sentido opuesto a la emanación, hacia la contemplación mística en que consiste la unión con lo supremo. Asimismo, de la mano de Plotino, los neoplatónicos rechazan a la materia por considerarla el Mal. De aquí que, como contrapartida, rechacen los sentidos (la sensualidad) como fuente de conocimiento: este se logra no de un modo racional, sino extáticamente, es decir, mediante el contacto del alma humana con el "Uno-todo". Por supuesto que este "contacto" ---esa "unión mística"- no era posible para todos: sólo los que renunciaran a la carne podían hacerlo. Como dice Plotino: "Ios objetos que nosotros amamos aquí son realmente mortales y nocivos, algo así como fantasmas cambiantes, que no podemos amar verdaderamente porque no constituyen el bien que nosotros amamos. El verdadero objeto de nuestro amor se encuentra en el otro mundo; podremos unirnos a Él, participar de Él y posecrlo, si no salimos a condescender con los placeres de la carne. Para quien lo ha visto es claro lo que digo: sabe que el alma tiene otra vida cuando se acerca al Uno y participa de Él, y que toma conciencia de que está junto a ella el dador de la verdadera vida"15.

En fin, con el neoplatonismo el Iema de la subjetividad activa - el gran tema moderno--- hace su aparición en la historia del pensamiento occidental. Como señala Bloch, "Plotino fue, en efecto, la primera aparición de un movimiento en contra de la contemplación pasiva, fue la aparición de la aclividad del alcance de lo supremo, de lo cual el hombre se puede considerar digno, o sea, del espíritu divino. Esto es lo que alcanza, hasta que está completamente lleno el secreto. Por consiguiente, se atrac el espíritu hacia uno mismo, penetrando primero en él; uno se reviste de él y se convierte en un nuevo nacido, que estí lleno de una energía distinta de la de la criatura"lt".

¿Cómo se articula la tradición platónica y neoplatónica con el pensamiento moderno? Gracias a la obra de Marcilio Ficcino (143.3-149)), quien traduce por primera vez a Platón y a Plotino al latín y al italiano. Pero no sólo eso: Ficcino, en su interpretación, no tanto en la fuente de luz. (el Uno-todo), sino en las cosas iluminadas. El más acá. Ficcino es un hombre del renacimiento. Con él se inicia la discusión científico-filosófica moderna. 
Ficcino, pues, retoma las ideas neoplatónicas del "Uno-Todo" situado en la cúspide de las ideas verdaderas. Asume que ese Uno-Todo ilumina aquello que jerárquicamente se le subordina hasta llegar las cosas terrenas (malcriales). Ahora bien, según Ficcino, es necesario centrarnos en las "cosas iluminadas" más que en la fuente de iluminación. Las cosas iluminadas son el mundo, lo terrenal.

Así, con este autor, estamos en los inicios de una "separación" entre lo terrenal (el mundo de las cosas) y lo divino (el Uno-Todo o I)ios) que se val a profundizar a medida que los nuevos tiempos - los tiempos modernos-vayan superando a los tiempos del anliguo régimen. A su vez, en esta separación comienzan a cobrar relevancia las cosas iluminadas, comienzan a converlirse en objeto de preocupación, mientras que lo divino (el Uno-Todo) se comienzal a poner entre paréntesis, a medida que se alcja de lo que pasal en el mundo. $\mathrm{Y}$, en tercer lugar, con Ficcino se reivindica la "autonomía" de la realidad terrenal. Pudo haber sido creada o iluminada por él (Uno-Todo), pero, una vez. que eso sucede, es necesario prestarle atención a lo creado o iluminado, con independencia de su creador o iluminador.

Otro autor clave en este periodo es Giovani Pico de la Mirándola (146.31494), quien se centra en una cosa que es iluminada: el hombre, cl homo faber. Más aún, los papeles se invierten: el hombre se halla en el centro del mundo, que es su casa, donde se habila, se mueve, hace su voluntad. Es decir, Pico de la Mirándola -en la línca de Ficcino— acepta la un mundo "autónomo" al que hay que prestar atención, pero se pregunta por la naturalezal del "habilante" de ese mundo, el ser vivo más dichoso, el más digno por ello de "admiración", gracias a la suprema generosidad de Dios que le ha concedido "Iener lo que elija, ser lo que quiera"17.

Para él, no cabe duda de que ese habitante por excelencia es el hombre, no los animales o las plantas. El hombre habita en el mundo haciendo cosis, adecuándolo para su comodidad. Vive en ese mundo como en su casia. Hi hombre es un homo faher; un ser que hace cosals, que interviene con insirumentos en el mundo. De la Mirándola, pues, da un paso delante de Ficcino: más que fijarnos en el mundo, lenemos que fijarnos en el ser que habila ese mundo: el hombre, que interviene en el mundo y lo cambia para su comodidad. Y lo asombroso de él, para Pieco de la Mirándola, es que se "mantiene abierı e indedeterminado en un universo donde todo tiene su puesto y dehe responder sin excentricidades a lo que marca su naluraleza. I)ios ha creado todo lo que existe pero al hombre le ha dejado, por así decirlo, a medio crear: Ie ha concedido la posibilidad de concluir en sí mismo la obra divina, autocreándose"

Se Irata, con Ficcino y Pico de la Mirándola de una visión renancentista, que va a ser el origen de planteamientos filosóficos y cientificos que se desarrollarán después. Además, se trata de una visión oplimista de la realidad y del hombre:

El sino de la modemidad: la búsqueda interminable de certezas 
el hombre puede hacer del mundo su hogar; el mundo está ahi para su conquista por el hombre.

Ese optimismo de Ficcino y de la Mirándola se verá cuestionado pronto por un personaje literario que introduce temas claves para entender la época moderna. Este personaje es Don Quijote de la Mancha (16(05), a partir de cuyas peripecias sale a luz el carácter ambiguo del mundo. Las tribulaciones de Don Quijote tienen que ver con las incerlidumbres que le provoca una realidad que no es como se presenta a sus ojos, que parece real pero es licción. bi héroe de Miguel de Cervantes no es el de Pico de la Mirándola -seguro de si mismo-, sino alguien que duda de sí mismo y de la realidad que lo rodea.

Don Quijote sospecha de la realidad, sospecha de su irrealidad, y esa sospecha lienc una raíz: la ausencia de cerlezas; es un individuo sin certezas, lanzado a la conquista de un mundo ambiguo, claroscuro, real e irreal, del cual, por lanıo, no sabe qué es lo va a deparar. No se desespera ni lo asume con tragedia. Se refugia en la ironia y el humor, dos acliludes lípicas de la modernidad.

En resumen: con Ficcino, Pico de la Mirándola y Cervantes se inicia la prohlemática cultural moderna. Sus elementos básicos son los siguientes: a) Dios (o la divinidad) puede ser puesto entre paréntesis, para prestar alención al más ací, al mundo; h) Este mundo eslá habitado por el hombre, quien cjerce sus habilidades sobre el mismo; y c) lil hombre puesto en el mundo -un espacio abierlo para sus habilidades-no liene cerlezas absolutas ni sobre sí mismo ni sobre la realidad.

Así las cosas, de lo que se trala es de buscar algún tipo de certeza, algún lipo de seguridad, sobre lo que es el hombre y sobre lo que es el mundo. Lisla hísqueda lienen que hacerse en el miss acá, concrelamente en el hombre, en los individuos. Esta va a ser la larea del pensamiento filosófico y cientílico moderno hasta la época aclual, cuando asistimos a la crisis de la modernidad. Én el marco de la discusión abierla por Ficcino, Pico de la Mirándola y ('ervanles cuatro vias se abren para buscar algín lipo de certeza en el sentido cjue hemos apuntiado

Una va a ser la "vía de la razón", en la cual se van a empeñar racionalistas como Descartes y Spinoza. Otra vía va a ser la "vía de los "sentidos", en la cual se van a situar empiristas como Bacon, Locke y Hume. Una tercera vía va a ser la de la "moderación", esbozada por autores como Miguel de Montaigne. Y la cuarta, la de la "ficción", la fantasía y los límites (la de la "locura"), uno de cuyos más claros exponentes va a ser el Marqués de Sade, el representante más completo de "esa corriente subterránea pero apenas clandestina [quc] es la otra cara del Siglo de las Luces"". Es en torno a estas cuatro "vías" que la modernidad emprende su búsqueda interminable de certezas. 


\section{En búsqueda de certezas}

La húsqueda de certezas que caracteriza a la modernidad se decanta, ante todo, en la línea del conocimiento seguro. Esta va ser la vía seguida por racionalistas y empiristas. Veamos sus planteamientos básicos.

\subsection{La "vía de la razón" y la "vía de los sentidos": Descartes, Spinoza, Bacon y Marx}

Hay una doble afinidad hásica entre racionalismo y empirismo: EI hombre es el punto de partida y ambas corrientes buscan una certeza para el arranque del proceso de conocimiento cientílico.

Los racionalistas van a buscar en la interioridad humana; su supuesto es que el apoyo (el sostén) que el hombre busca debe encontrarse (debe estar) en la razón. Rizoón: demostración argumentativa, ajena a los sentidos, sobre los problemas fundamentales del hombre, sus causals y leyes de movimienlo de los cuerpos. Asimismo, ese sostén debe quedar justificado por un ejercicio éserictamente racional, no contaminado por los sentidos.

\subsubsection{Descartes y Spinoza}

Descartes (1.596-16.5()) emprende con parlicular luerzal esal doble larea. Por un lado, va a sondear en la inlerioridad humana en huscal de una cerleza yue sea punto de partida metodológico para avanzar en el conocimiento. Por otro lado, lo va a hacer metódicamente, es decir, con una argumentación que apela cinicamenle a razones.

Su indagación se rige por el principio de les duda. Para llegar a la cerleza cue buscamos - nos dice- debemos dudar de lodo (sobre lodo de nuestros sentidos), menos de una cosa: que estamos dudando. liste "principio de la duda" nos conduce a la de una "cosa pensante" (rés cogrituns) opuesta a una cosal no pensante que esta fuera de ella: ress exlensus. tel lema "Pienso, luego existo" apunta precisamente al sostén que el racionalista Descartes andan buscando: puedo y debo dudar de todo, menos de una cosal que estoy pensando, es decir, que soy una cosal pensante.

Esta constatación me lleva, derivadamente (lógicamente), a aceplar mi exisencia, así como a aceplar la existencia de una realidad exterior y de una realidad divina que es causa de lodo (incluso de mis pensamientos sobre ella). Por lanto, "pienso, luego existo" debe entenderse no como "existo porque pienso", sino como "pienso porque existo, pero sólo llego a aceplar mi existencia -y la del mundo exterior y de Dios- desde mi naturaleza pensante. Entonces, esa realidad exterior y de esa realidad divina sólo existen para mi como subjetividad pensante que soy. Por lo menos, esto lo puedo dar por cierto.

¿Cuál es la estructura de mi subjetividad pensante? Es una cstructura mate-

\section{3}

El sino de la modernidad: lo búsqueda interminoble de certezos 
mática, concretamente geométrica. Y para conocer la res extensa, se la tiene que "traducir" a esta estructura subjetiva a través de procedimientos deductivos. Generalizaciones, cọnsecuencias particulares, derivadas lógicamente de aquellas. Esa es la tarea de la "ciencia racional". Es posible conocer el mundo que se abre ante los ojos del individuo. La condición para ello es el método adecuado, del cual ofrece Descartes la fómula: la duda metódica. Los límites no existen: el hombre tiene todo en su razón - pucsto por Dios- para conocer el orden del mundo que, si fue creado por Dios, tiene que ser un orden geométrico.

En suma, estamos en Descartes con un optimismo epistemológico exacerbado. No hay harreras para el conocimiento humano. ¿Y el error racional? ¿Y la equivocación lógica? Bueno, obedecen la intromisión de un "genio maligno" que se las arregla para perturbarnos, aunque sin alterar en lo fundamental el camino de la razón. "Cuidaré de no admitir en mi ciencia ninguna falsedad y prepararé también mi espíritu contra todas las astucias de ese gran engañador que, por potente y astuto que sea, nunca podrá imponerme nada"2il.

Spinoza (1632-1677) es el otro gran racionalista en la historia del pensamiento moderno. Menos radical que Descartes en algunas de sus tesis, abre las puertas -- desde el racionalismo- a la búsqueda de certezas no sólo en la subjetividad racional del hombre, sino en sus sentidos. En cierta forma, Spinoza hace eco de algunas ideas empiristas que habían sido abanderadas el siglo anterior por Francis Bacon (1561-1626). Así, Spinozal, en sus primeros pero importantes escritos, destaca la importancia de la "percepción" en el proceso de conocimiento. Más aún, introduce una jerarquía en las percepciones (4) desde la cual se avanza hacia el conocimiento.

La última de cllas (IV) permite la percepción de la "sola esencia" de una cosa. "Sólo, pues, el cuarto modo de pereepción comprende la esencia adecuada de la cosal y sin peligro alguno de error, por lo que es el que más debe ser empleado"=1. Una vez que damos ese paso, podemos pasar a entender las ideas verdaderas: "distinguiéndola de las demás percepciones e investigando su naturaleza para que conozcamos a partir de ahi, nuestro modo de entender y dominemos nuestra mente, de modo que entienda todas las cosas, que hay que entender, conforme a dicha norma; of reciendo como ayuda ciertas reglas y logrando, además, que la mente no se fatigue en cosals inútiles... De ahí se desprende que el método no es más que el conocimiento reflexivo o la idea de la idea. Y como no hay idea de la idea, si no se da primero la idea, no se dari tampoco método sin que se dé primero la idea. Por consiguiente, buen método será aquel que muestra cómo hay que dirigir la mente conforme a la norma de la idea verdadera dada"'?.

De este modo, Spinoza es un racionalista a carla cabal; para él la luente de las verdades fundamentales - entre la que destaca la verdad sobre Dios- está en la razón. Para él, las pereepciones son importantes, pero su última justifica- 
ción está en la razón. En palahras de Fernando Savater, "Spinoza nunca fue realmente cartesiano. Sus verdaderos intereses nunca fueron, como los de Descartes, de orden fundamentalmente congnoscitivo, científico; si Spinoza indagaha por un nuevo ordo mentis, era para conseguir por este medio un nucvo ordo mundi"'?.

\subsubsection{Bacon}

Entre tanto, la reinvidicación sin reparos de la percepción y los sentidos val a provenir del empirismo. Los empiristas, al igual que los racionalistas, están en la búsqueda de una certeza que sirva de punto de apoyo para el avance del conocimiento científico (cuyo modelo es el mismo de los racionalistas). lise punto de partida son los sentidos, "puente" entre el hombre y la realidad exterior (y también interior). Se trata, obviamente, de un uso sistemálicé de los sentidos, especificamente del sentido de la vista: se trata de "observar", de dejarse "afectar" por las cosas singulares.

Observaciones sistemáticas de determinados hechos o eventos deben llevar al conocimiento cientílico que consiste en la elaboración de "leyes generales" (regularidades). ¿Cómo? A lravés de la inducción, es decir, la derivación de un "enunciado general" a parlir de la observación sistemálica de casos perriculares. Así, las condicione's del conocimiento cientílico vienen dadas por el aparalo perceptivo humano y por los añadidos técnicos que este le pueda hacer.

Los limites vienen impuestos por el alcance de la observación: a mais poder de observación, mayores conocimientos. Las posibilidade's son infinilas, pues la tecnología potenciada por los avances de la ciencia favorece su desarrollo. I:I empirismo, pues, esta molivado por un optimismo epistemológico.

Un autor de primera importancia en la Iradición empirista es Irancis Bacon. Su intención expresa es demarcar lo cue él llama la "nueva ciencia nalural" de la vieja teología y vieja lïlosolía. Para él el mélodo antiguo es vicioso, especulativo: es el mélodo de la "anticipación mental". Ese método conduce a prejuicios, a juicios previos que "enturbian" el acercamiento del hombre a la naturaleza. Su método consiste, anle lodo, en "purgar" la mente de lodos los prejuicios. de lodas las ideas preconcebidas, teorias, supersticiones y creencias. I.os "ídolos" que la filosolia, la religión y la educación han inculcado a los hombres.

Limpia su menle de impurezas y prejuicios, puede el individuo acercarse a la naturaleza. Puede leer el Libro de la Naturaleza sin distorsionarlo. I a naturaleza no nos engañara, puesto que lo que engaña son los prejuicios, los idolos. Sólo tenemos que abrir los ojos; observar pacientemente y tomar registros delallados. Así se nos desvelara la esencia de las cosas observadas. "I a mejor demost ración - dice Bacon-, es sin comparación, la experiencia, siempre que se alenga estrictamente a las observaciones. Pues si se exliende una observacion a otros

El sino de la modernidad: la búsqueda interminable de certezas 
hechos que se cree semejantes a menos de emplear en ello mucha prudencia y orden, se engaña uno necesariamente"24.

Y más adelañte, añade: "no sólo es preciso investigar y recoger mayor número de experiencias y de distinto género de las que hoy poseemos, sino que también emplear un método completamente diferente, y seguir otro orden y otra disposición en el encadenamiento y la gradación de las experiencias. Una experiencia vaga que no tiene otro objeı que ella misma... es un simple tanteo, más propio para oscurecer que para ilustrar el espíritu del hombre; pero cuando la experimentación siga reglas ciertas y avance gradualmente en un orden metódico, entonces se podrá esperar mayor resultado de las ciencias"

En resumen, para Bacon, como señala Popper, "la observación pura, inmaculada, es buena; la observación pura no puede errar; la especulación y las teorías son malas, son la fuente de todo error. En particular nos luercen la lectura del Libro de la Naturaleza, esto es, nos llevan a malinterpretar nuestras observaciones"'sh.

\subsubsection{Marx}

Durante los dos siglos siguientes a los esfuerzos emprendidos por figuras como Descartes, Espinoza y Bacon, va a ser la filosofía hegeliana -tras la síntesis empirista y racionalista emprendida por Kant (1724-18(04)- la que mejor va a expresar el talante moderno en esta incansable búsqueda de certezas. Con Hegel (177()-1831) culmina un proceso de reflexión filosófica - de buis(jueda filosófica de cerlezas- que es inicia en los albores de la modernidad y que encuentra en él a su máximo sistemalizador. La filosofía de Hegel constituye una gran síntesis, un gran compendio sistemático, de lo que filosólicamente se había dicho hasta entonces en el terreno del pensamiento filosófico. Pero Hegel también es un punto de partida hacia otras elaboraciones intelecluales que, sin renunciar al estilo hegeliano de hacer filosofía, van a intentar desbordar los supuestos filosóficos hegelianos. El caso más llamativo va a ser el de Karl Marx (1818-188.3) $)^{27}$, quien expresamente — Iras las huellas de Ludwig Feuerbach (18041872) y la izquierda hegeliana- se propuso superar desde suspuestos hislóricomaterialistas el idealismo en el que aquella descansaba.

En efecto, auque crílico del hegelianismo, al que Marx acusa de poner la realidad al revés por hacer de la idea "sujeto" y de la realidad "predicalo" [según el esquema: sujeto (idea) $\ddagger$ predicado (realidad) ${ }^{2 k}$, cuando el esquema correcto es sujeto (realidad)łpredicado (ideas)], las calcgorías concepluales de Marx son hegelianas y neohegelianas. En efecto, para Marx se trala de "invertir" el esquema propuesto por Hegel, es decir, de hacer de la idea predicado de la realidad (sujeto). En este momento, los supuestos epistemológicos de Marx son fuertemente racionalistas: la realidad obedece a una lógica racional (dialéctica) 
que, para él, no es puesta por la cabeza de nadic, sino que está inscrita en la realidad misma ${ }^{2 y}$.

Hay que recordar la vieja tesis racionalista de la estructura geométrica de la realidad. Con Hegel se trata de una estructura dialćctica, procesual y dinímica. Sólo que para él estas propiedades corresponden a la Idea Absoluta (a una macro subjetividad). En sus primeros escritos -concretamente en su crítica a la filosofía del derecho de Hegel-, Marx asume este esquema, lo considera válido en lo fundamental, sólo que no es la Idea la que es dialéctica, procesual y dinámica sino la historia, cuya base es material. Este último punto - la base material de la historia-va a ser el filtro del empirismo en la visión cjue Marx está elaborando. Sin embargo, en los primeros escritos esa posibilidacl empirista -abierta por la influencia de Feuerbach—no es asumida en todas sus consecuencias, pese a que ya en su tesis doctoral sobre las filosofias de Inemócrito y Epicuro aparece esta veta sensualista y empirista de Marx.

El otro aspecto racionalista que destaca en Marx, en la ctapa que consideramos, es el de la "aprehensión mental" de la lógica (dialéctica) que gohicrna la realidad histórica. En sus textos juveniles adquiere un gran peso la prelensión de Marx de "dominar" mentalmente la lógica de la realidad, no mediante los sentidos, sino mediante la fuerza de la razón, del razonamiento. Demás estí clecir que esta pretensión nunca va a ser abandonada, al igual que nunca va a ser ahandonada la idea de que la realidad tiene una estruclura lógica (dialéclica) (jue es la que marca los ritmos y las posibilidades cambio histórico.

Así, en una primera aproximación al pensamiento marxiano las condiciones del conocimiento científico vienen dadas por la "aprehensión" conceptual de la lógica de la realidad; las posihilidades son tan amplias como consciente se sea de que el sujeto es la realidad y el predicado son las ideas; y los limites son impuestos por la inconsciencia que se tenga de la relación sujeto-predicado.

A partir de la Ideología alemana (1846-47) se comienza a operar un cambio en la perspectiva analítica de Marx. No se abandona los supuestos racionalistas, pero la influencia empirista comienza a hacerse sentir con mayor lucrza. Esta influencia tiene su fuente en los estudios que Marx hace de los clásicos de la economía política británica: Adam Smith (1723-179)() y David Ricardo (17721823). La influencia de los brilánicos Smith y Ricardo -muy enmarcada en la tradición empirista de Locke y llume-se hace sentir en el esluerzo de Marx por dar su proyecto de "socialismo científico" una fundamentación desde el análisis económico. A partir de este influjo económico, Marx retoma una intuición de sus primeros escritos: la importancia de la base material de la historia.

Su convicción firme, a partir de 1850, es que esa base material es la cconomía, es decir, la producción material de bienes (e ideas). Por tanto, el análisis de la estructura económica (capitalista) va a convertirse en su principal objetivo 
intelectual. Tres libros son claves en este propósito: La contribución a la crílica de la economía política (18.59), Ios cuadernos preparatorios para El Capilal, conocidos como (irundrisse, y los tres volúmenes de $E$ l C'apilal (cuyo primer tomo vio a luz eri vida de Marx) En esta segunda elapa cobra fuerza la idea de Marx de que su análisis del modo de producción capilalista sea un análisis tan riguroso como el de las ciencias naturales: es decir, un elaboración que de cuenta de las "leyes" y regularidades del capilalismo. Se trata, piensa Marx, de examinar la "analomía" de la sociedad hurguesa moderna, para lo cual hay que hacer un análisis científico de su funcionamiento estruclural.

En este empeño Marx hace suyas las pretensiones empiristas y positivistas de partir de la realidad (lo concreto) para, desde alli, elevarse hasta lo abstracto (lo concreto pensado), para luego volver de nuevo a la realidad para "verificar" la verdad de las abstracciones efectuadas. En palabras de Marx: "en el pensamiento lo concreto aparece, consiguientemente, como proceso de síntesis, como resultado, y no como punto de partida a pesar de que es el punto de partida real y, en consecuencia, también el punto de partida de la intuición y la representación" ". Este va a ser el célebre mélodo de la economía política, del cual Marx ofreció unas pocas reflexiones que hicieron historia en el pensamiento marxista posterior. Es en esta etapa, quizás la más influyente de Marx, en la que sus ideas económicas se suman al ambiente positivista dominante en Europa, Estados Unidos y, parcialmente, en América Latina. Desde este punto de vista, el Marx de la Contribución de 18.59 y de $1: 1$ Capiral está muy cerca, por su método y por sus supuestos epistemológicos, del empirismo y del positivismo.

Así, en esta etapa Marx va a insislir en el condicionamiento social del conocimiento científico. También va a dejar hastante bien establecido que las posihilidades del conocimiento se juegan en la capacidad del cientílico para hacerse cargo de sus condicionamientos; para distanciarse de ellos o ser crítico ante los mismos. Los limites del conocimiento, por su parte, se le van revelar, primero, como limires subjerivos que impiden "caplar" la realidad tal como es. En otras palabras, los limites del conocimiento van a provenir de una visión distorsionada de la realidad, es decir, de la ideología. Entonces, la ideología va a ser la gran enemiga del conocimiento cientílico de la historia y la sociedad. A la manera de Bacon, de lo que se trata es de combatir las ideologías (combate epistemológico y combate político), para que el conocimiento cierto pueda erigirse sin obstáculos. Pero los límiles del conocimiento lambién van a ser limiles ohierives: van a estar determinados por el "lugar" del científico social en los combates de su época.

En esta lectura de Marx que estamos haciendo se ve con claridad la filiación positivista de su planteamiento. Adicionalmente, Marx rinde tributo al positivismo en otro punto: la eficacia del conocimiento. Marx quiere validar científicamente sus aportes teóricos por su eficacia para incidir en el cambio histórico.

\section{8}

Realidad 83, 2001 
Sólo que a diferencia de positivistas como Comte y Spencer él le apuesta a la revolución, no a la reforma social. Y, por último, Marx fue en el londo un "solipsista metodológico". Después de todo, para él la empresa cientílica es un asunto absolutamente individual, es un reto que el cientílico armado con sus energías tiene que enfrentar.

En fin, lo dicho deja claro que Marx fue un hombre de una épocal, la cual marcó más de lo que normalmente se acepta su pensamiento y tesis fundamentales. Fue un hombre del siglo XIX. 'lanto es así que ni siquiera esluvo listo para dar el paso que estuvieron a punto de dar los positivistas lógicos, es decir, la consideración del lenguaje como eje fundamental de la socialización humana. ¿Y el racionalismo inicial de Marx? Bueno, ese racionalismo no desapareció: Marx siempre consideró que la realidad histórica tenía una estructura lógica (dialéctica) que podía ser aprehendida intelectualmente. Pero su insisiencia en que esaa realidad histórica era una realidad concreta que se convertía en punto de partida del conocimiento llevó a que el "paso" de la realidad a la inteligencia se sesgara hacia el positivismo.

Elaboraciones posteriores del marxismo no hicieron mis que enlatizar ya fuera en la vertiente hegeliano-racionalista del Marx o en la verliente positivistaeconomicista. Eso se explica porque el mismo Marx no logró (ni intentó) efectuar una síntesis entre racionalismo y empirismo a la manera de Kant. Tampoco lo intentaron sus principales continuadores de principios del siglo $\mathrm{XX}$ : I enin, Gramsci y Lukács. Quien hizo el intento lue Louis Althusser, en los años 40 y 50. Pero cuando se llega a Althusser la discusión epistemológica ya ha avanzado hastante y el influjo del estructuralismo se hace sentir con fuerza. (on Althusser", Marx es inscrito con contundencia en el racionalismo, pero las lecturas positivistas no han cejado en su intento por reivindicar su aporte "cientílico", como se pone de manifiesto en la interprelación "analítica" del marxismo elaborada por autores como Jon Elster y John Roemer".

Como quiera que sea. la filosolía posterior a Hegel no pudo no estar referida a él, incluso cuando pretendió revelarse contra el maestro. Aún ahora - en plena crisis de los metarrelatos y de las visiones totalizantes- es difícil sustraerse de las trampas hegelianas, sobre todo de la ambición totalizante que no deja de hacer su labor de zapa aun en quienes juran y perjuran haber renunciado a cualquier pretensión de alcanzar conceplualmente la totalidad de la realidad. Pocos lo dijeron con tanta claridad como Bloch: "Hegel es el maestro que puso los cimientos para la conciencia avazada moderna... en lo cue concierne a Hegel - maestro de Marx-, hay pocos pasados tan problemáticos como el suyo que nos salgan todavía al paso desde el futuro"".

El sino de la modemidad: la búsqueda interminable de certezas 


\subsection{La "vía de la moderación": Montaigne, Voltaire y Santayana}

Los racionalistas y empiristas emprenden una búsqueda que los conduce a habérselas con - y a fundamentar - un conjunto de postulados espistemológicos de cuya firmeza están convencidos. Es esie autoconvencimiento el que se trasluce en sus posturas intelectuales, mismo que fue heredado a la tradición filosófica que culmina en Hegel, quizás el filósofo moderno más convencido de la verdad de los supuestos que defendía. Pero no todo es convencimiento, conlianza y seguridad en el quchacer intelectual de la modernidad. También hay una veta de escepticismo no tanto acerca de lo que dicen otros - aunque también-, sino acerca de la solidez de los propios argumentos. En la modernidad curopea se perfila, en el siglo XVI, una veta intelectual que apuesta por lo provisional y lo conjetural, así como por la sospecha hacia las afirmaciones extremas y contundentes. Es decir, se perfila una veta intelectual "moderada", unos de cuyos más lúcidos exponentes va a ser Miguel de Montaigne (1533-1592), quien a lo más que se va a atrever es a "ensayar" algunas intrepretaciones sobre los problemas de su tiempo, el hombre, sus costumbres, vicios, hábitos y pretensiones. La brecha abierta por Montaigne va a ser continuada por Voltaire (1694-1778) y, más cerca de nosotros, por el español Santayana (186.3-1952).

\subsubsection{Montaigne}

En sus Ensayos ${ }^{34}$, Montaigne apunta ideas que anticipa preocupaciones que son las del hombre del siglo XXI. Asimismo, las ideas de Montaigne están teñidas de una actitud crítica hacia las pretensiones humanas de crecrse el centro y el fin de la creación. “¿Quién le ha hecho creer [al hombre] que este admirable movimiento de la bóveda celeste, la luz eterna de esas luminarias que giran lan por encima de su cabeza, los admirables movimientos del océano inlinito, han sido establecidos y se prosiguen a través de tantas edades para su servicio y conveniencia? ¿Se puede imaginar algo más ridículo que esta miserable y lrágil criatura, quien, lejos de ser dueña de sí misma, se halla sometida a la injuria de todas las cosas, se llame a sí misma dueña y emperatriz del mundo, no digamos para gobernar el conjunto?" "35.

Esta actitud crítica hacia la pretendida autocomplacencia de los humanos se expresa en el Capítulo L, titulado "De Demócrito y Epicuro". Allí nos dice Montaigne que mientras Demócrito encontraba vana y ridícula la naturaleza humana, por lo que se presentaba en público con un rostro burlón y risueño, Heráclito sentía piedad por esa misma condición, por lo cual estaba constantemente triste y con los ojos Ilenos de lágrimas. "Yo — dice Montaigne- me inclino mejor por la actitud del primer filósofo no porque sea más agradable reir que llorar, sino porque es más desdeñoso y nos condena más que el otro, y me parece que jamás podremos ser despreciados en el grado de nucstros mérilos" ${ }^{\text {?7 }}$. 
Y más adelante añade: "Pienso que no hay en nosotros tanta maldad como vanidad, ni lanta malicia como estupidez. No estamos lan afligidos por el mal, como provistos de inanidad... No somos lan miscrables cuanto viles... Demócrito considerábanos lan poca cosa que jamás podríamos lurbarlo ni alterarlo con nuestro contagio; abominaba nuestra comparizia no por lemor, sino por desdén hacia nuesiro tralo. No nos créia capaces de practicar ni el bien ni el mal”ix.

De lodos modos, sus ideas sobre el hombre - y sobre otros lópicos - son sólo opiniones - provisionales y discutibles- por ser el que las suscribe una persona más proclive al error (jue a la verdad. "listo que acpuí escribo son unas opiniones e ideas; yo las expongo según las creo alinadas, no para (jue se las crea. No busco otro fin (jue descubrirme a mi mismo, que acaso seré distinto mañana, si enseñanzas nuevas modilican mi manera de ver. No lengo autoridad bastante para ser creído, ni lo deseo, reconociéndome mal instruido para instruir a los demás"“".

Es decir, Montaigne es porlavoz de un esceplacismo no lanto acerea de lo que dicen otros, sino ante lodo acerca de lo que él mismo profesa. Isste escept icismo se sustenta en el carácer dubilativo de sus propias rellexiones. lo cual las hace siempre provisionales. A diferencia de la autosuliencia (pue se percibe en un Descarles o en un Bacon, la personalidad de Montaigne Irasluce una insaltislacción con lo que ha alcanzado, con la conciencia de que siempre cuuedan puntos pendientes por dilucidar y de los cuales no es seguro (jue se pueda dar cuenta. "Mis conceptos y juicios marchan vacilando, lambalciindose, Iroperando, y cuando avanzo lodo lo (que puedo, ni siquiera me siento medianamente salisfecho; diviso lodavia algo más allá, pero con vista allerada y nublada (que no puedo aclarar" +11 .

Además de esta aclitud de sospecha hacia las propias "concpuistas" intelectuales, hay en Montaigne un posicionamiento vital cuya característica lundamental es la moderación. Fsto lo lleva a evilar las situaciones extremas, ya sea a nivel existencial como a nivel intelectual. "Podemos practicar la virlud en tal forma - escribe- que llegue a ser viciosa, si la abrazamos con deseo demasiado áspero y de violencia". Más adelante, apunla: "gusto de las naluralezas lempladas y medianas; la lalla de moderación, si no me olende, me extraña al menos y me pone en aprielo para clasilicarla" ".

Para ilustrar esta exigencia de moderación al plano intelectual -especílicamente, al plano filosólico-- Monlaigne cila a Calicles, personaje platónico, quien — según nuesiro autor- "dice que el exceso de lilosolía perjudica, y aconscja no sobrepasarla de los límiles de lo étil; que lomada con moderación, es agradable y provechosa, pero que puede convertir al hombre en salvaje y vicioso: que desdeñe las religiones y las leyes comunes, que sea adversario de los humanos placeres, incapaz de todo gobierno político, de socorrer a sus semejantes y a sí mismo; merecedor, en lin, de ser impunemente abofeleado"s?

\section{El sino de la modernidad: la búsqueda interminable de certezas}


Luego, siempre en el plano intelectual, pero esta vez con una dedicatoria a los que gustan de hacer pasar ideas ajenas como propias, Montaigne les dice lo siguiente: "querer hacerlas pasar por propias resulta injusto y cobarde, no teniendo nada que les pertenezca, pretenden alcanzar méritos con lo que no es suyo, y además suprema torpeza, pues se contentan con la ignorante aprobación del vulgo y se desacredilan ante las gentes de entendimiento, que desprecian la incrustación de lo adquirido y de quienes, sólo, la alabanza tiene peso" ${ }^{\text {us }}$.

Y así por el estilo son los comentarios que este autor francés del siglo XVI va desgranando con una malicia y un aire juvenil propios de quien no está dispuesto a casarse con la seriedad y el aburrimiento. Este aire de sobriedad moral e intelectual va a ser respirado dos siglos después por Voltaire, digno continuador de Miguel de Montaigne, en quien la modernidad va a mostrar lo mejor de su veta crítica.

\subsubsection{Voltaire}

La obra de Voltaire ${ }^{14}$, conviene recordarlo, se inscribe en el movimiento ilustrado ${ }^{45}$ —esarrollado en Europa entre los siglos XVII y XVIII—, el cual fue de singular importancia en la historia de las ideas y las costumbres. Más aun, su irradiación todavia llega nosotros, hombres y mujeres que iniciamos la andadura del tercer milenio. Es conocida la célebre definición que Kant of reció de la misma de la Ilustración: "La llusiración es la liheración del hombre de su culpahle incapacidad. La incapacidad significa la imposibilidad de servirse de su inteligencia sin la guía del otro"ts. Así pues, la Ilustración, en la perspectiva de Kant, es una apuesta por la autonomía del hombre, una apuesta por su emancipación, pero no lograda por cualcjuier medio, sino por uno bien concreto: el entendimiento, la razón. Sólo quien usa su razón puede encaminarse hacia una mayoría de edad, es decir hacia la emancipación de la tutela de otros. Y emanciparse de la tutela de otros es atreverse a pensar por cuenta propia, apelando a las luces que la razón pueda aportar.

La llustración se ha entendido, pues, como una apuesta por la razón como instrumento emancipatorio. Sin embargo, el movimiento ilustrado no se agotó en la reivindicación de la razón, sino que alentó otras actitudes y príclicas que fueron consideradas por los mejores portavoces del movimiento - D'Holbach, Condoreet, Diderot, Voltaire- como útiles y necesarias para una convivencia humana medianamente decente. Entre estas actitudes y prácticas sobresalen las siguientes: la ironía, es decir, un dejo de burla ante quienes muestran una excesiva seriedad; la felicidad, esto es, el rechazo de todo aquello que es doloroso u ofensivo para la propia sensibilidad y bienestar; la liherlad de espirilu, o, lo que es lo mismo, estar abiertos a lo distinto, sin extrañarse de aquello que por diferente nos es desconocido; la tolerancia, que supone la disposición a aceptar no 
aquello con lo que somos afines, sino lo que es contrario a nuestras creencias más firmes; el sentido común, que invila a no descartar lo obvio, sino más bien a prestarle la debida atención; y el huén sentido, cuya exigencia máxima es que debe huscarse el mejor lado de las cosas antes que el peor. Se trata de actitudes tan necesarias para los hombres de ahora como los fueron para la ćpoca en la que fueron proclamadas.

De los cuatro pensadores que hemos mencionado, fue el último quien mejor expresó las virtudes reseñadas. En efecto, François Marie Arouet, conocido como Voltaire, sin dejar de insistir en sus escritos sobre la importancia de la razón como guía de la conducta humana, dedicó gran parte de sus reflexiones y de su vida a defender la ironía, la felicidad, la libertad de espíritu, la tolerancia y el sentido común. Al hablar de la figura de Voltaire, Fernando Savaler dice lo siguiente: "sin duda tuvo una concepción humoristica del trabajo intelectual, como cualquier persona seria e inteligente que se dedica a ćl, pero nunca buscó el chiste por el chiste ni se regodeó en bufanadas graluilas". Y ante la pregunta por el mayor título de gloria de Voltaire, Savater responde: "Ouc en su nombre no se puede perseguir a nadie por sus ideas, ni torlurar, ni declarar la guerra santa, ni excluir al prójimo de los beneficios de la humanidad"17.

El Diccionario filosófico es una de las mejores expresiones del espírilu volteriano. En el mismo encontramos, ordenados alfabélicamente --como es propio de lodo diccionario - los principales lemas y problemas que ocuparon a Vollaire, así como sus tomas de posición, las valoraciones y las rellexiones a las que esos temas y problemas lo abocaron. Evidentemente, muchos de los lemas y problemas abordados ya han perdido aclualidad; otros, sin embargo, conservan todavia su vigencia. Pero, más allá de los aciertos o desacierlos en los contenidos, el Diccionario filosófico of rece a los lecereses un éstilo de posicionarse ante la realidad, una forma de ver la vida, a los hombres y a las instiluciones, que sin duda resultará alracliva para quienes piensan que "el hombre no es lan perverso como se cree y a pesar de sus falsa opiniones y de los horrores de la guerra que le convierten en una fiera es un animal bueno y sólo es malo cuando se enfurece, lo mismo que los demás animales. Lo malo es que se le provoca con demasiada frecuencia" $\$$.

Li I Diccionario está lleno de ideas que son verdaderas joyas para cualquier espíritu en lucha permanente contra los prejuicios. Por ejemplo, asi, en la voz. "Cartesianismo" se lec lo siguiente: "la filosofía debe ser verdadera y justa: el filósofo no es francés, ni inglés, ni italiano, es cosmopolila... fil lilósofo, al rendir homenaje al genio de Descarles, debe pisotear las ruinas de sus sistemas". A listado de Voltaire quizás debería añadirse el filósofo latinoamericano -que todavia no logra superar su provincianismo.

Mientras tanto en la voz "Autores" dic dice: "el yo es siempre despreciable, decía Pascal. Ocupaos de vos mismo lo menos que podaís, porque el lector

\section{3}

El sino de la modernidad: la búsqueda interminable de certezas 
tiene tanto amor propio como el autor, y no perdona que queraís obligarle a que os aprecie. El libro debe recomendarse por sí mismo, si llega a abrirse paso. No digaís nunca 'mi:comedia fue honrada con tantos aplausos que me creo dispensado de contestar a mis adversarios', porque como es falso los que decís de los aplausos, nadie se acuerda de vuestra obra".

Finalmente, sobre la autoridad —en la voz que lleva ese títulos! - Voltaire anota lo siguiente: "Miserables humanos; ya vistaís ropón verde, ya os ciñaís turbante, ya os cubraís con traje negro o sobrepelliz, ya lleveís manteo o golilla, no os empeñeís nunca en que prevalezca la autoridad sobre la razón, o resignaos a estar en ridículo durante siglos, por ser hombres impertinentes, y a sufrir el odio público por injustos".

Nada mejor para terminar estas líneas dedicadas a Voltaire que un par de elogios que le profiere Fernando Savaler, a quien por muchos motivos - y dicho sea de paso- se puede considerar un volteriano a carta cabal. En el primero de ellos, Savater escribe lo siguiente:

"Por encima de todo, volvemos una y olra vez sobre la figura misma de Voltaire, el primer intelectual, combativo y pacífico, rencoroso y noble, cáustico y compasivo, presa de las pasiones y enamorado del razonamiento: un paradigma de la modernidad más que su mentor, a la par que inquietante y necesario. Lo dejó muy bien dicho en pocas líneas Heinrich Mann: "Voltaire, como la esperanza de la humanidad, se hunde en los estratos profundos de su pueblo, que no saben nada acerca de su cultura, que nada saben acerca de sus carencias y de sus límites, y para los cuales él es siempre la liberlad misma"" "\$2.

En el segundo, dice lo siguiente:

“[Voltaire] no Iransigió con ningún descrédito del mundo ni se dejó aguar la fiesta por las morales cuyo paso de carrera nunca puede alcanzar el más brioso galope de la vida. Fue demasiado hedonista para ser justiciero, demasiado inteligente para no ser compasivo. Hay en él una fascinante amalgama de lo más elevado y de lo más bajo: sobre todo, es terrible, casi insoportablemente moderno... Sí, como dijo Nielzche, fue "un gran señor de las lelras". El último gran señor de las letras y primer inteleclual" "‘s

\subsubsection{Santayana}

La obra de este ilustre español -que escribió en inglés, enseñó en Harvard y vivió en Inglaterra, Alemania y París- expresa lo mejor de la continuidad de la tradición ilustrada en el siglo XX, un siglo plagado de valores y actitudes abiertamente contrarias a las propagadas por la llustración. En plena fragua del "asal- 
to a la razón" en la cultura europea ${ }^{54}$, Sanlayana supo defender los fueros de la razón ${ }^{55}$, aunque se trató de una defensa caracterizada por un prudente esceplicismo. Para Santayana, la razón es, a la vez que severa, bondadosa con el alma. "La severidad de la razón desengañándonos de estas vanas pasiones constituye una auéntica bondad para con el alma; tampoco es una severidad arisca, sino paternal e indulgente hacia todo placer afecluoso" $"$.

Precisamente, de lo que se trata es de fundar una "élica racional" que esté a la altura de la constitución física y racional del hombre -ese ser inteligente que se "desarrolla en el interior de un estúpido y lleva atraillado a un orale" que se sustente en una moral natural. "Es un método fijo-dice Santayana- de alcanzar finalidades a las que el hombre se siente atraído en virtud de su constitución física y moral. Por este hecho la ética racional se ve separada de la mala compañía de los sistemas de moral artificiosos, verbalistas e injustos, los que al dispensarse de toda relación con las dotes y con la experiencia del hombre, no hacen sino demostrar lo ajenos que son a la vida" ".

La razón, pues, no debe estar desconeclada de la vida, que es anterior a ella; lampoco debe estar desconectada de la experiencia: "la lunción de la razón es controlar la experiencia; por eso resulta que es tan necesaria para dicha linalidad el que esté abierla a nuevas impresiones" "." Es en virlud de este doble anclaje de la razón -en le vida y la experiencia- que se puede llevar una vida racional, la cual "se compone de los momentos en que no sólo se produce la rellexión, sino que ésta resulta, además eficia" ${ }^{\prime \prime(x)}$.

Eficaz. ¿.para qué? Ante todo, para resistir los embates de lo irracional, es decir, eso repulsivo y terrible dentro del ser humano y que se observa en el "maniálico, el avaro, en el horracho, o en el mono" aprender a aceptar que al final de la vida viene la muerle como cuando acepta que "el final de una fiesta liene que ser el relirarse a dormir" Y ello porque "la Iransitoriedad de las cosas es esencia a su existencia física, y no es en modo alguno triste en sí misma”.". En tereer lugar, para enlientar a las liranías, sobre todo por su carga de "estupidez. arrehalada y onminpresente" "., En cuarto lugar, para resistir al misticismo, especialmente en lo que liene lanalismo y de alentado contra la perfección de la naluraleza liumana: "el ideal del misticismo es exactamente contrario al ideal de la razón; en lugar de perfeccionar la naturaleza humana, trata de abolirla; en lugar de edilicar un mundo mejor, sería capaz de socavar los fundamentos hasta del mundo que hemos edilicado ya" ${ }^{\text {"tol }}$. I in quinto lugar, para no vivir soliviantados por una ilusión, puesto que "es mejor vivir en armonía con la verdad" que negarse a "ahandonar una ilusión venida a menos" "ha . En sexto lugar, para no ser presals de la intolerancia, propia de quienes se creen a sí mismos unos iluminados"st. İn séptimo lugar, para ser portadores de una verdadera "simpalía”, es decir, de una simpalía que permite a quienes la han asumido vitalmente ser sensibles a los sulrimientos de los demás, siendo felices con la felicidad de ellos: se trata de una condición magnifica, "porque depura la

El sino de la modemidad: la búsqueda interminable de certezas 
voluntad natural sin debilitarla, of reciéndole por el contrario un desarrollo nuevo ya adecuado, un desarrollo predeterminado por completo por la estructura fundamental de la naturaleza humana"17. En oclavo lugar, para llevar una "vida sana" lanto para el alma como para cl cuerpo y para lo cual "bastan un poco de experiencia, un poco de reflexión y un poco de sinceridad" "אk. Finalmente. para vivir en libertad, no a la manera clásica —es decir, en "una especic de liberlad forzada y artificiosa... reservada a una aristocracia ascética en la que el heroísmo y el refinamiento estaban infeclados de perversidad"(1) - sino a la manera inglesa", porque "hasta en el gran respeto que muestra el inglés por la riqueza y la condición social, honra más a la liberlad que al poder"71 y porque "la libertad política [a la manera inglesa] es un signo de independencia moral y económica""? .

En definitiva, como señala Fernando Savater: "Santayana creyó en la fuerza de la razón, pero nunca le atribuyó poderes omnímodos, que son en último término imprescindibles si el sistema ha de tener auténtica verosimilitud. Por el contrario, mostró su escepticismo ante determinadas disquisiciones del más alto vuelo que han apasionado a los máximos clucubradores... Por eso no logró ocupar un puesto entre los más importantes logros teóricos de este siglo el sistema de Santayana: demasiado escéptico y poético, demasiado razonable y discreto, demasiado obviamente congruente con toda la tradición filosófica, demasiado subjetivo y demasiado reverente con los hábitos de la objetividad, demasiado a mbicioso en sus aspiraciones y demasiado modesto en sus medios"

Por último, no se puede hablar de Sanlayana sin hacer alusión de lanto a su "materialismo" como su "idea de filosofía". Pues bien, el materialismo de Santayana supone, por un lado, exigencia de fidelidad a los hechos como fundamento de la verdad - una verdad cuya posesión absoluta es incompalible con el eslar vivo ${ }^{74}-y$, por otro, aceptación de la "creatividad de la malcria". Sobre esto último, Santayana hace la siguiente reflexión: “„por qué el amor humano y la religión se atormentan tanto si son los amos del mundo? Si uno y otra ordenan milagrosamente y la materia obedece, ¿no es acaso porque la malcria empezó por crearlos a ellos y les dictó los mandamientos que ellos tenían que dictar"75. O, en otras palabras, "todo nos impulsa suavemente a ver los asuntos humanos de una manera científica, realista, biológica, a considerarlos como acontecimientos que surgen, con todas sus connotaciones espirituales, en el dominio de la materia"7n. Dicho más tajantemente: "la humanidad constituye una raza de animales que vive en un mundo material. Me engañaría a mí mismo y al lector si no lo admiliera así... todo aquel que, celoso del honor de la vida, el orden y el espíritu, vuelve la espalda al naturalismo como si este hubiera de desiruir aquellos supremos bienes, paréceme que ha errado tolalmente la concepción de su estado existencial"'77.

A propósito de la filosofía -la escéptica: "la que enseña que lodas las dignidades son una engañifa y que la sabiduría no es sino el don de saber sacar el 
mejor partido posible a lo que nos cae en suerte"7N - Sanlayana nos dice que es un saher debe estar anclado en los hechos y en la materia. Del filósofo dice lo siguiente: "un filósofo no puede desear ser engañado. Su filosolía constiluye una declaración polílica de la presencia de los hechos; y, por lanto, su primer cuidado debe consistir en indagar y reconocer de buen grado lodos los hechos pertinentes a su acción o sentimiento; ni menos ni, necesariamente, mís. I a búsqueda de la verdad es una lorma de valenlía y un libosolo puede muy hien amar la verdad por si misma, en cuanto está dispuesto a enfrentarse al destino, cualquicra que este pueda ser, con deleite cuando sea posible, con resignación cuando sea necesario, y no pocas veces con diversión" "7".

Y es que, en definitiva, la húsqueda de la verdad es el mejor correctivo contra fanatismos, ilusiones infundadas y sueños. "Cuando el corazón se inclina hacia la verdad, cuando la prudencia y el amor de la prosperidad dominan la voluntad, la ciencia desplazarí por fuerza de una manera insensible a la adivinación, y el sentimiento de reverencia se transferirá desde las religiosidades Iradicionales hasta el poder desnudo que trabaja dentro de la Naluraleza, y sancionará la sahiduría mundana y las virtudes higiénicas más bien que las máximas de los fanálicos y los sucños de los santos" "*n!"

Para terminar con este aparlado dedicado a Santayana, vamos recordar algunas de las frases no lan elogiosas que le dedicó Berirand Russel ${ }^{* 1}$, de quien el español, por su parle, dijo que le inspiraba poca conlianza su análisis de los hechos, pero que en cambio le resultaba admirable cuando se molaba de los actual y jugueteaba con lo inactual ${ }^{x}$.

"Por mi parte -escribe Russel- nunca pude tomar en serio a Santayana como filósofo profesional, aunque creo que ha desempeñado una lunción útil al sacar a luz, como crítico, puntos de vista que hoy no son corricntes. El ropaje americano con el que aparecen sus obras oculta al gún tanto el carácter exiremadamente reaccionario de su pensamiento... (omo sus charoladas botas, es demasiado melifuo y pulimentado. La impresión que se liene al leerlo es la de que se flota sobre un río de aguas apacibles, lan ancho que con dificultad puede verse alguna de sus orillas; así, cuando de vez. en cuando surge un promontorio ante la vista, uno se sorprende de que aparezea algo nuevo, tan inadvertido resulta el movimiento. Me parece, al lecrle, que voy enterándome de cada frase casi de una manera sonánbula; pero que soy incapaz, después de algunas páginas, de recordar de lo que se Irataba" ${ }^{\text {" }}$.

\subsection{La "vía de la locura"}

Como dijimos antes, la modernidad conoce una cuarla vía para buscar sus certezas: la de ficción, la lantasía y los límites (la de la "locura"), uno de cuyos más claros exponentes va a ser Donatien Alphonse Francois, Marqués de Sade. 
Ante todo, hay que señalar que de Sade se ha enfatizado hasla la saciedad la perversión desaforada que aparece en sus escritos, considerados por más de alguno meros panllelos pornográficos. Esla "leclura" de Sade ha impedido, en muchos casos, una ínterpretación más ponderada de su obra que, además de una dimensión literaria, tiene una dimensión filosófica que no conviene perder de vista. Sade, en efecto, se considera a sí mismo un filósofo, pero -como señala Ana Nuño- en la acepción que el lérmino luvo para los Ilustrados: "no un profesor universitario, ni un sabio musitando verdades entre el Kifiso y el lliso, sino un pensador implicado en las luchas ideológicas y políticas de su liempo,

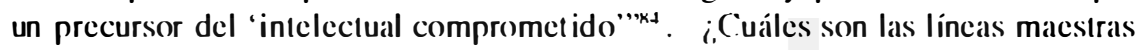
del pensamiento sadiano?

En primer lugar, hay en Sade una racionalización hasta limites verdaderamente obsesivos del binomio placer-dolor. En esto, Sade no sólo se inscribe en las exigencias filosóficas de su tiempo -caracterizadas por la disputa entre racionalistas y empiristas-, sino que lleva hasla extremos mortales las exigencias de "orden" propias de ambas tendencias filosóficas. La "filosofía de la crucldad" de la que Sade es portavoz. decidido se funda, en efecto, tanto en las exigencias de la razón como en las exigencias de la sensibilidad. "Distinguimos dos tipos de crueldad -escribe en filossofía c'n el rocador-: la que nace de la estupidez y que, al no ser nunca producto de la razón y de la reflexión, asimila al individuo asi nacido con el animal feroz: esta crucldad no procura ningún placer... El segundo tipo de crueldad, fruto de la suprema sensibilidad de los órganos, sólo es experimentada por seres extremadamente delicados, y los excesos a los que ella conduce no son sino refinamientos de su delicadeza" ${ }^{\text {" }}$.

La obra Los 120 días en Sodoma es la mejor expresión de la obsesión por el orden que recorre la obra de Sade: "Iodos los dias a la hora de lavantarse — se lee en los "Reglamentos" de los 120 dias- será a las diez de la mañana. En este momento los cuatro jodedores que hayan estado de servicio la noche anterior visitarán a los amigos, llevando cada uno de cllos un muchachito; pasarín sucesivamente de una habitación a otra: obedecerín las órdenes y deseos de los amigos, pero al principio los muchachos que llevarán con ellos sólo servirá de acompañamiento, porque queda decidido y acordado que las ocho virginidades de los coños de las muchachas no serín violadas hasla el mes de diciembre, y las de sus Iraseros, asi como las de los traseros de los ocho muchachos, lo serán en el curso del mes de enero, y eso con el fin de acrecentar la volupluosidad mediante el hosligamiento de un deseo inflamado sin cesar y nunca satisfecho, estado que debe necesariamente conducir a un cierto furor lúbrico que los amigos cuidan y provocan como una de las situaciones más deliciosas de la lubricidad"ksh.

La lógica que rige el pensamiento de Sade -como hace notar Albert Camuses una "lógica de las pasiones" que "derriba el orden tradicional del razona- 
miento y coloca la conclusión antes que las premisas... [Sade| codilica la maldad natural del hombre. Construye meticulosamente la ciudad del poder y del odio, como precursor que es, hasta poner en cifras la libertad que ha conquistado. Resume entonces su filosofía en la fría contabilidad del crimen: 'asesinados

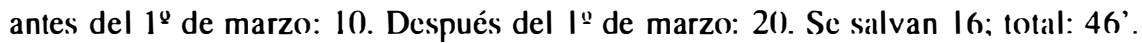
Precursor sin duda, pero todavía modesto, ya se ve"

En segundo lugar, al leer con detenimiento a Sade queda claro que para él no hay límites para el dolor que se puede provocar o para el placer que se puede recibir, pues los existentes, cualesquicra que estos sean, siempre se pueden sobrepasar. "Ahora veo con toda claridad, tras conocer vuestros principios - clice Eugenia-, que existen muy pocas cosas que puedan considerarse delitos en el mundo, y que podemos entregarnos en paz a nuestros deseos, por más extravagantes que puedan parecer a los imbéciles" "‥ Esos deseos pueden ser siempre llevados a escalones de dolor-placer cada vez más extremos, cuyo punto de llegada no puede ser otro que la muerte. El camino a recorrer para ser fieles a esta lógica de las pasiones y del deseo pasa por la sodomia, las fantasias sacrílegas y el gusto por la crucldad".

A Sade - escribe Camus- "el sueño y la creación le han dado un equivalente ridículo a la satisfacción que el orden del mundo no le da. El escrilor, por supuesto, no tiene nada que negar en él mismo. Para él, por lo menos, los límites se borran y el deseo puede ir hasta el final. En esto Sade es el hombre de letras perfecto... Su mérito indiscutible es el haber ilustrado al primer golpe, en la clarividencia desdichada de una rabia acumulada, las consecuencias últimas de una lógica rebelde cuando ella olvida la verdad de sus orígenes. Listas consecuencias son la totalidad cerrada, el crimen universal, la aristocracia del cinismo y la voluntad de apocalipsis"'"к1.

En tercer lugar, Sade reivindica la posesión absoluta de los otros - los más débiles, como la virtuosa Justine, condenada a las vejaciones más salvajes" hasta los límites de su destrucción. "La única cosa que hacemos, al entregarnos a la destrucción, no es sino producir una variación en las formas, pero de ningún modo apagar la vid, y está entonces muy por encima de las fuerzas humanas el probar que puede existir ningún crimen en la pretendida destrucción de una criatura, de cualquier sexo o edad, y de la especic que os imaginéis"'”.'. Se trata, para Sade - como anota Camus- de gozar hasta los mayores extremos concebibles, “y el máximo de goce coincide con el máximo de destrucción. Poseer lo que se mata, acoplarse con el sufrimiento" ${ }^{43}$.

En cuarto lugar, la lógica que gobierna el universo sadiano - la “lógica de las pasiones" - hunde sus raices en la Naturaleza que es sexo, placer y destrucción. En el sexo, el placer y la destrucción — siendo esta última la culminación de aquéllos- es la naturaleza quien aconseja al hombre, "y el hombre que destruye a su semejante es para la naturaleza lo que la peste o el hambre, que 
lambién son enviadas por su mano, la que se sirve de todos los medios posibles para oblener cuanto antes la maleria prima de la destrucción, absolutamente esencial para sus obras" ${ }^{9 / 4}$. En su apucsta por la Naturaleza, Sade niega brutalmente a Dios, al" liempo que hace de aquélla un poder de destrucción. "La naluraleza, para él, es sexo; su lógica lo conduce a un universo sin ley, donde el único dueño será la energía desmesurada del deseo"xs . ¿Y Dios?" "Es una locura - die Sade- que no liene el mundo más de veinte seguidores, y que la religión que invocan no es más que una lábula ridículamente inventada por bribones cuyo interés en engañarnos es evidente ahora" "'",

La visión que tiene Sade de la Naturaleza es coherente con las lecturas mecanicistas y deterministas en boga en la época en la que el Marqués hizo sus reflexiones. Concretamente, Sade se nutre de las ideas del Barón D’Holbach. expuestas en su Sistema de la naturaleza (177() $)^{17}$. Sin embargo, la perspectiva de Sade no se agota en su tiempo, sino que llega hasta el siglo $X X$. cuando el influjo de los enfoques estructuralistas y sistémicos ha llevado a ver a los seres humanos como meras marionelas de una lógica que hace que la libertad sea una quimera y que "una fuerza más poderosa que nosotros nos empuja a todo lo que hacemos" Es . Es lo que pensó, por ejemplo, L ouis Althusser de la ideología como constituyente de los individuos como sujetos ${ }^{(1)}$ o lo que defienden autores como Niklas Luhmann cuando dan al sistema social una autosuciencia tal que lo que sucede en la sociedad y con los hombres - hienestar, guerras, pobreza, delerioro ecológico- no obedece más que a sus necesidades autopoiéticas, es decir, sus operaciones de autorreproducción mediante las cuales un sistema crea su propia estructura y los elementos que la componen ${ }^{\mid 1 \times 1}$.

En quinto lugar, - como se vislumbra por lo dicho antes- de esta absolutización de la Naluraleza extrac Sade los fundamentos de si aleísmo. Giracias a Ficcino y a Pico de la Miríndola, en la modernidad se inició un proceso de "puesta entre paréntesis" de la divinidad: el la creación podía ser considerada con independencia del creador que, empero, siempre estabal allí, como garante último de la lógica de la realidad (Hegel). Sade da un paso más allá: la Naluraleza no necesila de un Dios creador que la justifique. "Y ya que es posible - dice el moribundo al sacerdote- que la naluraleza por sí sola haya hecho lo que alribuyes a tu Dios, ipor qué quieres adjudicarle un amo? La causa de lo que no comprendes es, quizás, la cosa más simple del mundo. Perfecciona lu física y comprenderás mejor la naturaleza; depura tu razón, desecha lus prejuicios, y ya no tendrás necesidad de lu Dios""II!. Insiste el moribundo: "en consecuencia, desde el momento en que lu Dios no sirve para nada, es perfectamente inútil. Se supone que lo inútil es nulo y que todo lo que es nulo es nada. De modo que para convencerme de que lu Dios es una quimera, no necesilo otro razonamiento que aquel que me proporciona la certeza de su inutilidad"III. 
Dicho de otro modo, rechazar a Dios es un asunto de mera razón, de demostración y comprensión racionales: "es perfectamente imposible creer en lo que no se comprende. Entre la comprensión y la fe deben existir vínculos estrechos, la comprensión es el primer alimento de la fe; donde no hay comprensión, la fe esta muerta. Y los que en ese pretendieran posecrla, se engañan. No te creo capaz de creer en el Dios que predicas, porque no sabrías demostrírmclo, porque no está en ti definírmelo, y en consecuencia no lo comprendes" "II!. Si Dios no existe, lo que suceda entre los hombres es algo que depende de las reglas impuestas por la Naturaleza, cuyo imperativo mayor es, según el moribundo del texto sadiano, "hacer tan felices a los demás como uno mismo deséaría serlo, y nuncal causarles más daño del que uno mismo quisiera recibir"|1 .

Por último, el Marqués de Sade, a tono con su tiempo, barrunta una sociedad ideal, la cual, por un lado, se edificará según el modelo del castillo cerrado sobre sí mismo; y, por otro, habrá de estar fundada en el liberlinaje. Vivir en esta sociedad supone asumir como "deberes del hombre" las acciones inspiradas en el libertinaje, "entre las cuales se distinguen particularmente aquellas que se consideran alentatorias contra lo que cada uno debe a los otros, vale decir la prostituciom, el adulterio, el incesto, la violación y la sodomia"los. Asimismo, las priclicas libertinas tienen un "templo" para su realización: "un reliro apartado y solitario, como si el silencio, el alejamiento y la tranquilidad fuesen los vehículos poderosos del libertinaje, y como si todo lo que comunica a estas cualidades un terror religioso a los sentidos tuviera evidentemente que prestar a la lujuria un atractivo miss" "Ix. Lo que Sade reivindica es - como señala Barthes- un lugar de "autareuía social", donde "una vez. encerrados, los libertinos, sus ayudantes y sus subditos forman una sociedad complela, dotada de una economía, una moral, una palabra y un ticmpo, articulado en horarios, en trabajos y en fiestas" "in"

I as consecuencias que se siguen del discurso sadiano son, por una parte, la "soledad del más fuerle", del que sobrevive a la desirucción de los más débiles. "El mais poderoso, el que sobrevivirá, será el solitario, el Unico, del que Sade ha emprendido la glorificación; él mismo, en delinitiva. llelo acjui cjue linalmente reina, amo y Dios" Naluraleza: "al amar a las personas, sólo debemos pensar en nosolros mismos; amarlos por ellos es un engaño. No está en la Naluraleza inspirar a los hombres otros movimientos, otros sentimientos que no sirvan sino para obtener alguna otra cosa; nadie es tan egoísta como la naturaleza" es decir, del desborde de lo permitido — racional y sensiblemente - en una búsqueda sin término, en una "búsqueda imposible para escapar a la desesperanza y que, sin embargo, acaba en desesperanza, de una carrera de la servidumbre a la servidumbre y de la prisión a la prisión. Si sólo la naluraleza es verdadera, si en la naturaleza únicamente el deseo y la destrucción son legílimos, entonces de destrucción en destrucción, ya no bastando el mismo reino humano para la sed de sangre, hay que correr a la aniçuilación universal"'ll". 
Por lo anterior, Sade puede ser considerado como un pensador de los límites, es decir, como un pensador que se dio a la tarea de reflexionar filosóficamente sobre la sexualidad humana -en sus dimensiones de perversidad y erotismo-sin hacer concesiònes a la moral oficial vigente en su tiempo.

Uno de los autores que con más contundencia ha señalado el talante filosófico de la obra del "divino Marqués” ha sido el mexicano Octavio Paz. "Después de miles de años de vivirlo — dice Paz-, esto es, de recrearlo y repetirlo, de representarlo, el hombre empezó a pensar el erotismo. Sade fue uno de los primeros... Sade no nos propone un cuadro de pasiones sexuales, aunque sus obras son muy ricas en esta materia, sino una idea de hombre. Inclusive lees 120) journées de Sodome, en la que aparecen seiscientas perversiones, algunas descritas por vez primera, es algo más que un catálogo de prácticas e inclinaciones extrañas y feroces"'।'.

Más adelante, señala Paz:

“A partir de ciertos principios que considera evidentes, sin recurrir a la experiencia directa o a la observación, utilizando hasta el máximo el mélodo deductivo y combinatorio, es decir, por un inmenso trabajo de especulación, Sade llega a ciertas verdades. Estos principios constiuyen su filosofía. Gracias a ellos descubrió realidades que, por explosivas y atroces que nos parezcan, no dejan de ser nuestras. Así pues, no deben de ser lan caprichosos o delirantes como generalmente se piensa. En suma, el principal interés de la obra de Sade es de orden filosófico. Su originalidad mayor consiste en haber pensado el erotismo como una realidad total, cósmica, es decir, como la realidad. Su pensamiento, no por disperso menos riguroso, es a un tiempo crítico y sistemático. Y ofrece esta particularidad: con la misma coherencia, ingenua y fastidiosa, con que los filósofos utopistas construyeron la ciudad del hien, Sade levanta un edificio de ruinas y llamas. Su obra no es tanto una crítica como una utopía. Una utopía al revés"'I?

En suma, Sade fue, indudablemente, un hombre de su ticmpo. Pero, ahora como en su época, su lógica "remueve conciencias y vapulea convicciones"1"? Este hombre, de quien se dijo que "había corrompido con sus escritos impíos y liberlinos y que ha manchado su nombre con tantos crímenes"1/4, se atrevió a llevar hasta sus últimas consecuencias la lógica de la destrucción. Reflexionó sobre esta lógica y pretendió justificar lo injustificable. Se precipitó en los abismos de la soledad y la locura, pues terminó siendo víctima no sólo de sus propios fantasmas, sino de la incomprensión y la condena de sus contemporáneos. Una vez que el cadáver de Sade fue exhumado (aproximadamente hacia 1819-20), en su diagnóstico de su cerebro, Domoutier - asistente del frenólogo Spurzheim, un discípulo alemán de Gall- dice lo siguiente: 
“La organización cerebral del marqués de Sade, considerada desde el punto de vista frenológico, es uno de los ejemplos más frecuentes en los cuales se encuentran los contrastes más acusados... Ya sea a consecuencia de los cambios de cambios operados en la organización de su cerebro, o por la influencia de circunstancias del mundo exterior, el caso es que el resultado ha sido una depravación tal en la moral y la filosofía del marqués de Sade que se componen de la mezcla más amorfa de vicios y virtudes, actos carilativos y crímenes, odio y amor. Nacida de las pasiones más vergonzosas e impregnadas de sentimientos de oprobio e ignominia, lan monstruosa concepción, de no haber sido obra de un loco, habría hecho a su autor indigno del nombre de hombre y manchado para siempre la memoria de su posteridad"1/s.

Como un loco: así lo vieron muchos de sus contemporáneos. Otros lo vieron como un depravado, un egoísta y un perverso. Pocos reconocieron lo que despućs reconocieron mentes lúcidas como la de Camus: que con Sade "empiczan realmente la historia y la tragedia contemporáneas" "in. Es decir, que Sade es el padre espiritual — junto con Stirner, Dostoyeski y Nictzche"1' — de los que en el siglo $\mathrm{XX}$ "han rechazado cualquier otra regla que no sea la del deseo y el poder, han corrido al suicidio o a la locura y han cantado el apocalipsis" $11 k$. () lo que es lo mismo: de quienes transitaron de la "rebelión melafísica" a la "rebelión histórica"; los que del "asesinato de Dios" pasaron al "asesinato polílico": los que hicieron de la revolución "la consecuencia lógica de la rehelión metafísica" "1".

\section{Reflexión final}

La "búsqueda de certezas" es el sino de la modernidad: esa ha sido la idea que ha animado estas páginas. ¿Tiene fin esa búsqueda? Tal parece que no; al parecer se Irata de una húsqueda inacabada, lo cual hace de la modernidad - para usar una frase muy querida de llabermas- un "proyecto incompleto". ¿Cuál es la situación actual de esa húsqueda? Muchos sostienen que, ante todo, se ha arribado a una nueva histórica — "posimoderna"-, en la cual la húsqueda de certezas ha desembocado en un cuestionamiento de los "Iogros" filosóficos y científicos obtenidos a partir de la lógica de la modernidad. A la vez que dichos logros, se cuestionan los supuestos melafísicos (Iolalizanles) y científicos (dominadores, manipuladores) que los sostienen. La reivindicación de los microdiscursos, los compromisos efímeros y de corto plazo, el hedonismo, el nihilismo y una visión esteticista de la vida serían algunos de los rasgos del clima cultural de la postmodernidad"20". Así, la "búsqueda permanente de lo nuevo" sería la marca distintiva de quienes quieren alejarse a grandes zancadas de la modernidad. Pero, ¿no es esto una radicalización de la modernidad y no tanto un ir más allá de ella?

El sino de lo modernidad: lo búsquedo Interminable de certezos 
Es precisamente por ello que Oclavio Paz no se muestra muy conforme con nombrar "postmoderna" a la elapa actual de la historia occidental. Para él, es indudable que la modeṛnidad agolado sus energías intelectuales y morales, pero ese agotamiento no se expresa en un "post", sino en algo absolutamente distinto, que por ahora no liene nombre. Asistimos - dice Paz - al final de liempo rectilíneo: "la historia moderna ha cambiado de orientación y... asistimos a una verdadera revuelta de los tiempos... El liempo cambia y con él nuestra visión del mundo, nuestras concepciones intelectuales, el arte y la polílica"':2. Los modernos respondieron crílicamente al tiempo rectilíneo, de la mano de Marx y Rimbaud, con la revolución y la rebelión. "No sé cuál séa la forma del liempo nuestro: sé que es una revuclta... El tiempo rectilíneo intentó anular las diferencias, suprimir la alteridad; la revuella contemporánea aspira a reintroducir la otredad en la vida hislórica"' "z. Este es el eslado aclual de la búsqueda moderna; las cerlezas que se creía poseer se han derrumbado. Y en este mundo "desbocado" de principios del tercer milenio la búsqueda continúa, aun a sabiendas de que —como escribe Anthony Guiddens- "nunca seremos capaces de ser los amos de nuestra historia"'?.

San Salvador, 21 de seprie'mbre de 200$) 1$

1. Las lesis hásicals de esce ensalyo fucron expuestas por el autor en la introducción al curso "Filosofía idealista alemana y posilhegeliana", en el segundo semestre del aïo 2001

2. Para una vision glohal del Renacimiento, cir. Ilalc, J. R.. L.a liuropa del Renacimic'noo. 1480-1.520. México, Siglo XXI, 1979)

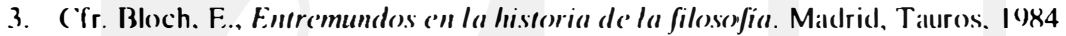

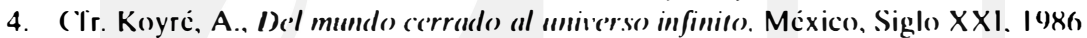

5. Fen el renacimiento surgio un ideal, según la fórmula célebre de Juan Addintong Symonds (184()-184.3): "cl del hombre pugnando por converlirse en el monarca del universo en que liene el privilegio y el destino de vivir". Addinlong Symonds, J.. "FI renacimiento en llalial". En Ilerrera lhaiñes. A., Anlologia del Renacimic'nto y" la llustración. México, UNAM, 1972, p. 20)

6. Kovré, A. Estudios de historia del pensamicneo cientifico. México, Siglo XXI, 1976, p. 4.3

7. Ibid.

8. Según Ilerher Bullterlicld, Ios origenes de la revolucion cientifica del siglo XVII puede ser rastreada en los siglos XI y XII. (Tr. Bullerlichl, II. Los orige'ne's de la ciconcia moderna. Maldrid, Taurus, I) I)

9. Koyré, A., Del mumdo cerrado al uminerso infinito, p. 2

10. (Cr. North, D. (.. Thomas. R. P., l:I nacimic'nes del mundo occidental. Ina mueva historia económica (9)(1)-17(1)). Mixico. Siglo XXI, 197.3, pp. 147 y ss.

11. Salntayana, G.. Los reinos del ser. México. F'( $\mathrm{F}$. 1959), p. 27

12. (Fr. Paz., O., "I os hijos del limo". Fn l.a casa de la pressencia. Poessia e historia.

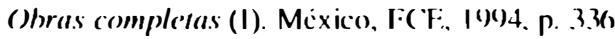


13. A la misma estirpe de estos precursores pertenece, sin duda alguna, Lirasmo de Rotterdam (1466-1536), para quien si hien el hombre depende de Dios, lambién goza de una cierla liberlad para tener una conducla moral autónoma

14. Hirschman, A. O., De la economia a la politica y más allá. Linsayos de penetracioin y superación de fronteras. México, FC.E, 1984, p. 1.31

15. Plotino, Eneada sexta. Madrid, Aguilar, 1975, p. 402

16. Bloch, E., Entremundos en la historia de la filossorfica, p. 127

17. Pico de la Mirándola, G., "Oración sobre la dignidad del hombre". Lin Herrera Iháñez, A., Antologia de'l Renacimiento y la llustración.... p. 2.3 .3

18. Savater, F., Las preguntas de la vida. Barcelona, Ariel, 19(9), p. 97

19. Nuño, A., "Prólogo" a Marqués de Sade. Elogion de la insurreccción. Madrid. Ell vicjotopo, 2001, p. 12

20. Descartes, "La melalísica". Lin el Discurso del método y otros tratados. Madrid, EDAF, 1970, p. 171

21. Spinoza, Tratado de la reforma del antendimiento. Principios de Filosofía de I)e's cartes. Pensamientos metafisicos. Madrid, Alianza, l(988. p. 89)

22. Ihid.

23. Savater, F., "Spinoza y la alegria de lo necesario". Lin Misterios gozosos. Madrid, Espasa Calpe, 1995, p. 158

24. Bacon, F., Novum organum. Mćxico, Porrúa, |(9)।, p. 5.3

25. Ihid., p. 71

26. Popper, K., "¿Razón o revolución?" Lin l:I mito del marcon comin. Llna defensa de la ciencia y la racionalidad. Barcelona, Paidós, 1997, p. 89)

27. La obra de Marx es plural y de muy distinto nivel de anailisis. En consonancia con ello, asi es de variado el estatuto epistemológico de la misma. P'or un lado, estín las carlas y panfletos (por cjemplo, el Manificsto del partido comunista), cuyo claboración analítica es, por lo general, muy simple. En segundo lugar, estion los escritos clasificados como de juventud: por ejemplo, los Anales franco-alcmame's y Los manuscritos económicosfälosifficos (1844). Aqui la claboración analitical y conceplual es más compleja; constiluye un desalio importante desentrañar sus supuestos epistemológicos. En tercer lugar, estion los llamados escritos de madurez. precedidos por escritos de transición como La Ideologia Alemana y La sagrada familia, concrelamente El Capital y la Comtrihución a la critica de la comomia politica. Por último están los análisis de coyuntura, lanto periodísticos como de fondo (entre estos últimos, por ejemplo, se tienen textos con un elevado nivel de anilisis, como El dieciocho hrumario de Luis Bomaparte, publicado en 18.52)

28. Cfr. Hegel, G.W.F., Introducción a la historia de la filosofía. Madrid, Aguilar. 1968

29. Cfr. Marx, K., Critica de la filosonfía del e'stado y del derecho de Hégel. México. Cultura Popular, 1977; D’Hondt. J.. Do Hegel a Marx. Buenos Nires. Amorrorlu. 1972, pp. 218 y ss.

30. Marx, K., Lineas fundamentales de la critica de la c'conomia politica ((irundrisse). Primera mitad. Barcelona, Crílica, 1977, p. 24

31. Cfr. Althusser, L., "Sohre la relación de Marx con Hegel”. Lin I)’Hondt, J. (('omp.), Hegel y el pensamiento moderno. México, Siglo XXI, pp. 93-120 Roies. A.. Lcectura de Marx por Althusser. Barcelona, Laia, I(974

32. Roemer, J. E. (Comp.), El marxismo: una perspectiva analitica. México, F( I: I)89)

El sino de la modernidad: la búsqueda interminable de certezas 
33. Bloch, E., Sujeto-ohjeto. El pensamiento de Hegel. México, F(E, 1985, pp. 12 y ss.

34. Montaigne, Ensayos. México, CONACULTA-Ocćano, s.f.e.

35. M. de Montaigne, Ensayos, cilado por Fernando Savater en Las preguntas de la vida. Barcelona, Ariel, 1999, p. 1.31. Lisle tex10 citado por Savater, del capilulo XII de los Ensayos, no aparece en la edición de CONACULTA-Océano, que es precisamente la que estamos manejando en esic ensayo

36. M. de Montaigne, Ensayos. Cap. L, p. 142

37. Ihid., pp. 142-143

38. Ihid., "De la educación de los hijos", ('ap. XXVI, p. 67

39. Ihid., p. 65

40. Ihid., "De la moderación". Cap. XXX, p. 100)

41. Ihid., p. I0I

42. Ihid., "De la educación de los hijos", p.p. 66-67

43. (on leves modificaciones se reproduce aqui el comentario que hizo el autor de estas notas sobre el Diccionario filosófico de Voltaire, publicado en la sección "V:I rincón del libro" de la Revista Realidad. No. 76, pp. 503-505

44. Contraparlida intelectual de un proceso de cambio cultural caracterizado por una crisis religiosa y por la "emergencia de una conciencia hurguesa autónoma" que, justamente, se traducia en una problemalización de la fe y de las verdades emanadas de la Iglesia y la tradición. Cfr. Groethuysen, B., l a formacioin de la conciencia hurguesa en Francia durante el siglo XVIII. México, FCE, I()8.5

45. Kant, I., “¿Qué es la Ilustración?”. En Herrera Ibáñez, A.. Antología del Renacimicnto y la llustración. México, UNAM, 1972, p. 409

46. Savater, F., "Voltaire: libre, comprometido y leliz". Prólogo a Voltaire, Diccionario filosófico. Madrid, Temas de Hoy, 1995, Vol. I, p. XV

47. Voltaire, Diccionario filosífico, voz "Caridad", p. 9.34

48. Ihid. P. 399

49. Ihid., p. 282

50. Ihid., p. 283

51. Savater, F., "Cándido: el individuo sale de la historia”. En Despicrta y lece. Madrid, Alfaguara, 1998, pp. 94-95

52. Savater, F., “iVive Voltaire!”. En Misterios gozosos. Madrid, Espasa Calpe. 1995. p. 175

53. Según la célebre expresión de (ieorg Lukícs. (fr. Lukács, (i., El asalto a la razoín. La trayectoria del irracionalismo desde Schelling hasta Hitler. México, 1976

54. En 1906, Santayana publicó cinco importantes volúmenes sobre la razón: I a razón en el sentido común, La razón e'n la socicidad, l.a razoin en la religión, La razón en el arte y La razón c'n la ciencia

55. Santayana, G., Atomos de pensamiento. Madrid, Aguilar, 1956, p. 152

56. Ihid., p. 45

57. Ihid., p. 142

58. Ihid., p. 59

59. Ibid., p. 41

60. Ihid., p. 69

61. Ihid., p. 268

62. Ihid., p. 75

6.3. Ihid., p. 3.34 
64. Ihid., p. 219

6.5. Ihid., p. 382

66. Ihid., p. 143

67. Ihid., p. 40

68. Ihicl., p. 323

69. Inglaterra es por excelencia, para Santayana — según comenta Jorge Luis Borges"el hogar de la felicidad decente y del tranquilo placer de ser uno mismo". Borges, J. L., Textos cautivos. Madrid, Nlianza, 1999, p. 94

70). Santayana, G., Atomos..., Ihid., p. 25.5

71. Ihid., p. 69)

72. Savater, F., "Santayana: huésped del mundo". En Misterios gozosos. Madrid, Espasa Calpe, 1995, p. 193

73. Santayana, G., Los reinos del ser.... p. 1.3

74. Santayana, G., Atomos.... p. 374

75. Santayana, G., Dominaciones y potestades. Buenos Aires, Suramericana, 1954, p. 10

76. Ihid., pp. 17 y ss.

77. Santayana, G., Atomos.... p.256

78. Santayana, (i., Los reinos del ser. pp 11-12.

79. Santayana, (i.. Atomos.... pp. 37.5-376

80. En su Retratos de memoria y otros c'nsayos. Madrid, Alianzal. 1976

81. Santayana, G., Alomos.... p. 159

82. Russel, [3., Ihid., pp. 95-(97

8.3. Nuño, A.. "Prólogo"”.... pp. 14-1.5

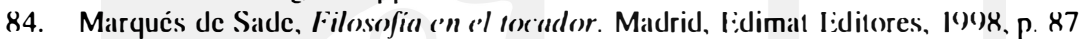

8.5. Marqués de Sade. Los 120) dias e'n. Sodoma. México, Juan P'ablos Editor, lo()8, p. 59)

86. Camus, A., "Ll hombre rebelde". En Ohras comple'as, II, Madrid, Aguilar, 1971, Pp. 621 y 624

87. Marqués de Sade, Filossofia c'n el tocador.... p. 68

88. Ihid., p. 78

89. Camus, A., "l:1 hombre relhelde" .... p. 627

9(). (Tr. Marqués de Sade, Los informunios de la virhucl. Madrid, Ldimat, 19(9)

91. Marqués de Sade, Filosofia c'n el tocador.... p. 17.3

92. Camus, A., "El hombre rehelde" "... p. 624

93. Marqués de Sade, Filosonfia c'n el tocador..., p. 173

94. Camus, A., "El hombre rehelde".... p. 619

95. Marqués de Sade, Los 120) días ('n Sodoma, p. 68

96. Nuño, A., "Prólogo"..., p. 16

97. Marqués de Sade, Iulic'lle. Madrid, Fundamentos, 1908, p. 21. vol. I

98. Althusser, L., La filosonfia como arma de la revolución. México, Siglo XXI. 1991, pp. 1.38 y ss.

99. Crr. Izusquiza, I., La sociedad sin hombre's. Niklas Luhmann o la teoria como escándalo. Barcelona, Anthropos, 190(), pp. 109 y ss.

10(). Marqués de Sade. "Diálogo entre y un sacerdote y un moribundo". En Elogio de la insurrección..., p. 26 y 31

101. Ihid., p. 31

102. Ihid., p. 27

El sino de la modernidad: la búsqueda interminable de certezas 
103. Ihid., p. 44

104. Marqués de Sade, Filosofía en cl tocador..., p. 154

105. Marqués de Sade, Los 120 dias en Sodoma..., p. 52

106. Barthes, R., Sade, Fourier, Loyola. Madrid, Catedra, 1997, p. 27

107. Camus, A., "El hombre rebelde"..., p. 626

108. Marqués de Sade, Filosofía en cl tocador..., p. 122

109. Camus, A., "El hombre rebclde"..., p. 625

1 10. Paz, O., "Un más allá erótico: Sade". En Idéas y costumbre's. Usos y símbolos. Obras completas II. México, F(E, 1993, p. 48

111. Ihid.

112. Suárez, G., Ciudadano Sade. Barcelona, Plaza y Janćs, 1999, p. 3.57

113. Según dice el Prefecto Dubois en su informe sobre el comporlamiento de Sade en Charenton (donde el Marqués había sido internado en 1803). (fr. Lever, M.. Domatic'n Alphonse Fracois, marqués de Sade. Biografia. Barcelona, Scix Barral, 1994, p. 5() 1

114. En Ihid., p 525

115. Camus, A., "El hombre rebelde"..., p. 628

116. Según la brillante interpretación de Camus en "Ll hombre rchelde"... pp. 618-658

117. Ihid., p. 676

118. Ihid., pp. 681 y ss.

119. Para una visión de conjunto de los planteamientos postmodernos, (Tr. Mardones, J. M., Postmodernidad y cristianismo. El desafio del fragmento. Santander, Sal Terrac, 1988

120. Paz, O., "Una forma que se busca". En Idcas y costumbres..., pp. 6.31-6.32.

121. Paz, O., "La revuelta". En Ideas y costumbres..., p. 643

122. Guiddens, A., Un mundo deshocado. Los cefectos de la glohalización en nucstras vidas. Madrid, Taurus, 2000), p. 17 